\title{
Business intelligence and the telecommunications industry: can business intelligence lead to higher profits?
}

\author{
J. O'Brien \\ Centre for Information and Knowledge Management \\ University of Johannesburg \\ Auckland Park \\ 2006 \\ South Africa \\ jethro.obrien@kpmg.co.za \\ J.A. Kok \\ Department of Information and Knowledge Management \\ University of Johannesburg \\ Auckland Park \\ 2006 \\ South Africa \\ jakok@uj.ac.za
}

\section{Contents}

1. Introduction

2. What is business intelligence (BI)?

3. What is the purpose and functionality of BI?

4. What is the nature of the competitive advantage that BI can provide in the telecommunication industry?

5. How can the utilization of BI improve profitability in the telecommunication industry?

5.1 Improving profitability in terms of pure profit and return on investment

5.2 Improving profitability in terms of achieving a competitive advantage

6. What is the contribution that management can make when utilizing BI in the telecommunications industry?

7. Empirical survey

7.1 Survey sample

7.2 Questionnaire

7.3 Data analysis

7.4 Findings

8. Recommendations

9. Linking general theory and concepts to practice

10. Conclusion

11. References

Key words: Telecommunications industry, business intelligence, competitive intelligence, decision support system, South Africa 


\section{Introduction}

Organizations are finding it increasingly difficult to increase profits as competition in the marketplace continually pressurizes margins. Organizations will have to do more to enjoy sustainable profits in the future and information technology could arguably be the key to assisting management with the task of increasing profits on a sustainable basis. Business intelligence (BI) could be the competitive advantage for organizations to increase profitability.

South Africa is faced with an unemployment rate of over $40 \%$ and it is not desirable that costs are contained by reducing staff. It is clear that innovative ideas should be looked at to ensure that organizations continue to make profits. Information management programmes offer the necessary tools to ensure that efficient and strategic decisions are made.

$\mathrm{BI}$ is an advanced computer application that can calculate efficient business decisions given time, management, distance, historical and cost data. Simply put, it is a set of concepts and methods to improve business decisions. However, many organizations are unaware of the potential benefits of BI. Some organizations do not know that such applications exist. A further question now arises: if chief information officers are aware of the tools that are available, do they possess the resolve to integrate the available technologies into their organizations?

This research sought to confirm the hypothesis that BI can improve profitability in the telecommunications industry in South Africa. This is contingent on management applying the BI correctly and timeously. In addition, the research study addressed the following subproblems relevant to the hypothesis:

- How can BI be applied in the telecommunications industry?

- In what way can BI improve profitability in the telecommunications industry:

$\circ$ In terms of pure profit?

- In terms of achieving a competitive advantage?

- What is the contribution that management can make when utilizing BI in the telecommunications industry?

Other relevant topics that were addressed include:

- The definition of BI

- The purpose and functionality of BI

- The functional competitive advantage that BI can supply.

To confirm the main hypothesis, it is necessary to understand the definition of BI, what it comprises and how it operates.

\section{What is business intelligence (BI)?}

The phrase 'business intelligence' refers to:

- A set of business processes

- The technology used in these processes

- The information obtained from these processes.

Organizations typically gather information to assess the business environment and cover fields such as marketing research, industry or market research and competitor analysis. Competitive organizations accumulate BI to gain a sustainable competitive advantage and may regard such intelligence as a valuable core competence in some instances.

Persons involved in BI processes may use application software and other technologies to gather, 
store, analyse and provide access to data (also known as the BI cycle). Some observers regard BI as the process of enhancing data into information and then into knowledge. The software aims to help people make 'better' business decisions by making accurate, current and relevant information available to them when they need it (Wikipedia 2005a).

Executive information systems (EIS) lost their popularity in the late 1990s when it became clear that it is only worthwhile to create a separate system for executives in only a few large corporations. Information that is useful to top-level executives is often also of use to lower-level executives and managers throughout the organization.

With the introduction of the intranet and corporate portals, the traditional EIS has become a part of an enterprise information system. An enterprise information system (EIS) is often synonymous with the term BI and such tools are now integrated with e-commerce and other Web-based systems (Turban, McLean, Wetherbe, Bolloju and Davison 2002:460).

Turban, et al. (2002:460) go further and define BI as a computer-based decision analysis usually done online by managers and staff. It includes forecasting, analysing alternatives and evaluating risk and performance.

McLeod and Schell (2001:45) argue that BI is an addition of competitive intelligence (CI). Competitive intelligence entails researching the business environment to influence its emerging strategy for business development (Wikipedia 2005b). It is defined as actionable recommendations arising from a systematic process, involving planning, gathering, analysing and disseminating information on the external environment, for opportunities or developments that have the potential to affect a company or a country's competitive situation (Wikipedia 2005b).

In addition, McLeod and Schell (2001:45) believe that fierce global competition has forced companies to rethink the way in which they gather information. Today, the gathering, storage and dissemination of environmental information represent an important computer application in many organizations around the world. Originally, the application was dedicated to gathering information on the firm's competitors and thus the term competitive intelligence (CI) was coined.

When defined broadly to include information on all environmental elements, the proper term is BI. The nature of defining BI is very complex. However, it can be concluded that BI is a type of decision support system (DSS). A decision support system is an arrangement of computerized tools used to assist managerial decision-making within a business. A DSS usually requires extensive data 'massaging' to produce information (Rob and Coronel 2002:613)

\section{What is the purpose and functionality of BI?}

A basic BI infrastructure comprises both business processes and practices and technological components. The technological components used to support the business processes comprise tools that include online analytical processing (OLAP), data warehouses (DW), data mining (DM), business performance management, document warehouses, text mining, executive information systems (EIS) and decision support systems (DSS) (Wikipedia 2005a).

According to McLeod and Schell (2001:45-47), BI involves five basic tasks, namely to collect data, to evaluate the data, to analyse the data, to store intelligence and to disseminate intelligence. Each of these facets will be discussed in greater detail.

- To collect data. The organization may acquire either primary data or secondary data. Primary data are gathered internally. Secondary data are gathered by someone else and are then made available to the firm.

- To evaluate data. All of the data, secondary as well as primary, should be evaluated prior to use to ensure their accuracy.

- To analyse data. The purpose of the analysis step is to transform data into intelligence.

- To store intelligence. Intelligence must be stored (preferably digitally) in a way that allows easy 
retrieval.

- A sophisticated approach to dissemination is to prepare an intelligence profile for each user, describing in a coded form the intelligence topics that the user wants to monitor.

There is a large difference between a data warehouse, a data mart and BI. The data warehouse or data marts are physical data stores that provide tools and technologies to manage data. BI consists of applications on top of these data stores (Hasheem 2001).

BI surpasses reactive reporting; it lets users get proactive with data within the organization. With BI tools, users can analyse and manipulate data, create 'what if' scenarios to generate reports or gain insight into various trends that are hidden within the reams of data that an organization stores. The evolution of BI itself and the impact of electronic ways of doing business have resulted in the emergence of new concepts within BI. On the database front, there is the emergence of multidimensionality to replace or prop relational database management systems.

The rows and columns approach of relational databases does not offer the 360-degree, multidimensional view that business users require. On the other hand, multidimensional databases map the characteristics that are important to the organization to store data along various dimensions not just rows or columns. As a result such databases manifest themselves as cubes that offer much deeper insight and analysis into the workings of the organization (Feng 2002:133-134).

Figure 1 illustrates a conceptual BI infrastructure. It utilizes both top-down and bottom-up approaches. Comprehensive BI encompasses the following:

- Information integration activities: Data sourcing and extraction, transformation and loading (ETL), operational data stores (ODSs), data warehousing and data marts.

- Data analysis activities: Ad hoc query support, online transaction processing (OLTP), online analytical processing (OLAP), statistical analysis, data mining, data visualization, text mining and Web mining.

- Intelligence deployment activities: Canned and customized report generation, BI Web portals and other deployment methods.

Figure 1 Conceptual business intelligence infrastructure (Source: Gartner Group 2001)

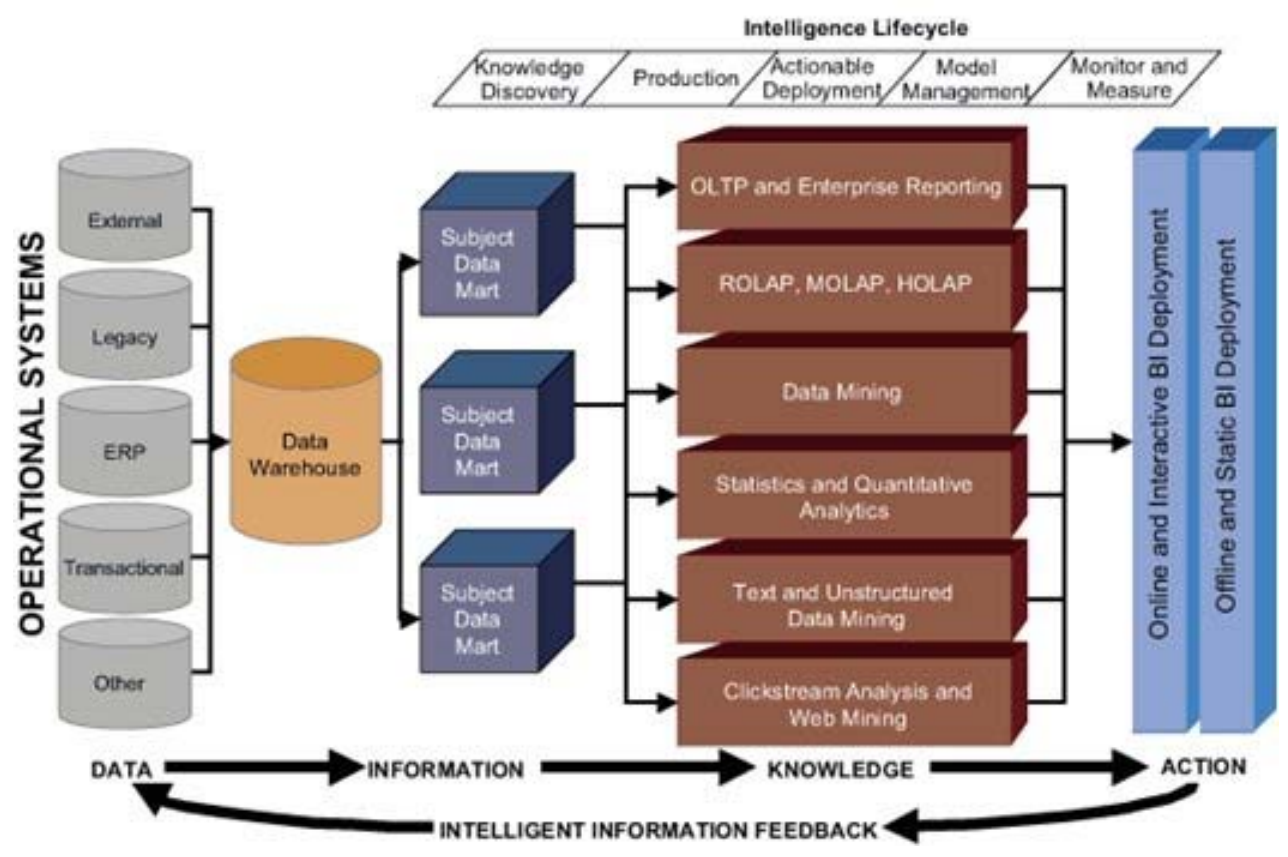

4 What is the nature of the competitive advantage that BI can provide in the telecommunication industry? 
BI tools need to rise to meet the challenges of the knowledge worker of today. It is not just top management or a few technical analysts who require information or analysis. Various groups of people need to analyse data in different ways to arm themselves with the information they need to do their day-to-day jobs effectively. This information is turning out to be a powerful tool in today's competitive markets.

BI technologies and processes attempts to help people understand data more quickly so that they can make better and faster decisions and, ultimately, to assist them to attain their business objectives.

The key drivers behind BI objectives are to increase organizational efficiency and effectiveness. Some BI technologies aim to make the flow of data within an organization faster and more accessible (e.g. making standard reports easier to build, maintain and distribute). Yet other, newer BI technologies take a more aggressive approach by redefining existing processes with new, more streamlined ones that eliminate entire steps or create new capabilities that are beyond the reach of legacy approaches.

Changes in today's business environment, combined with the competitive advantages of new technologies, make sticking to legacy techniques problematic. Major changes are driving the need for new tools and new approaches to decision making:

- Ruthless competition is placing huge pressure on earning profits. Survival is dependent on the organization that acts and reacts the quickest.

- Electronic data and databases are literally exploding in size. Today's sophisticated enterprise resource planning (ERP) systems, e-commerce systems, data warehouses and the Web are greatly expanding the amount of data available. Old tools are not up to the challenge of sorting through large amounts of data and analysing these data to produce intelligence.

- Pressure on profits and the increasing pace of business have led to flatter and leaner organizations. Wide-scale retrenchments provide organizations with negative perceptions (Sun Microsystems 2006).

BI applications focus on gathering, storing, analysing and providing access to data from many different sources to help users make better business decisions. Therefore, by taking advantage of more accurate firm-wide data, these systems can support very fine-grained decisions for guiding the firm, coordinating work activities across the enterprise and responding rapidly to changing markets and customers (Laudon and Laudon 2004:348). Essentially, BI applications are designed to improve performance, identify opportunities and threats, increase efficiency and reduce costs. Middle and senior management can use BI applications to help them define strategies, search for opportunities, identify problems and substantiate actions.

BI can support decision making in a number of ways. It can automate certain decision procedures (e.g. determining the highest price that can be charged for a product to maintain market share). It can provide information about different aspects of the decision situation and decision process, such as what opportunities or problems triggered the decision process, what solution alternatives were generated or explored and how the decision was reached. Finally, BI stimulates innovation in decision making by helping managers question existing decision procedures or explore different solution designs (Dutta, Berend and Dalebout1997).

The ability to explore the outcomes of alternative organizational scenarios, use precise firm-wide information and provide tools to facilitate group decision processes can help managers make decisions that help the firm achieve its strategic objectives (Forgionne and Kohli 2000).

Table 1 illustrates the reasons why American customers are implementing BI and data warehouse (BIDW) systems in four major vertical industries namely government, financial services, retail and the telecommunication industry.

Table 1 Reasons for implementing business intelligence and data warehouse systems (Source: Sun Microsystems 2006) 

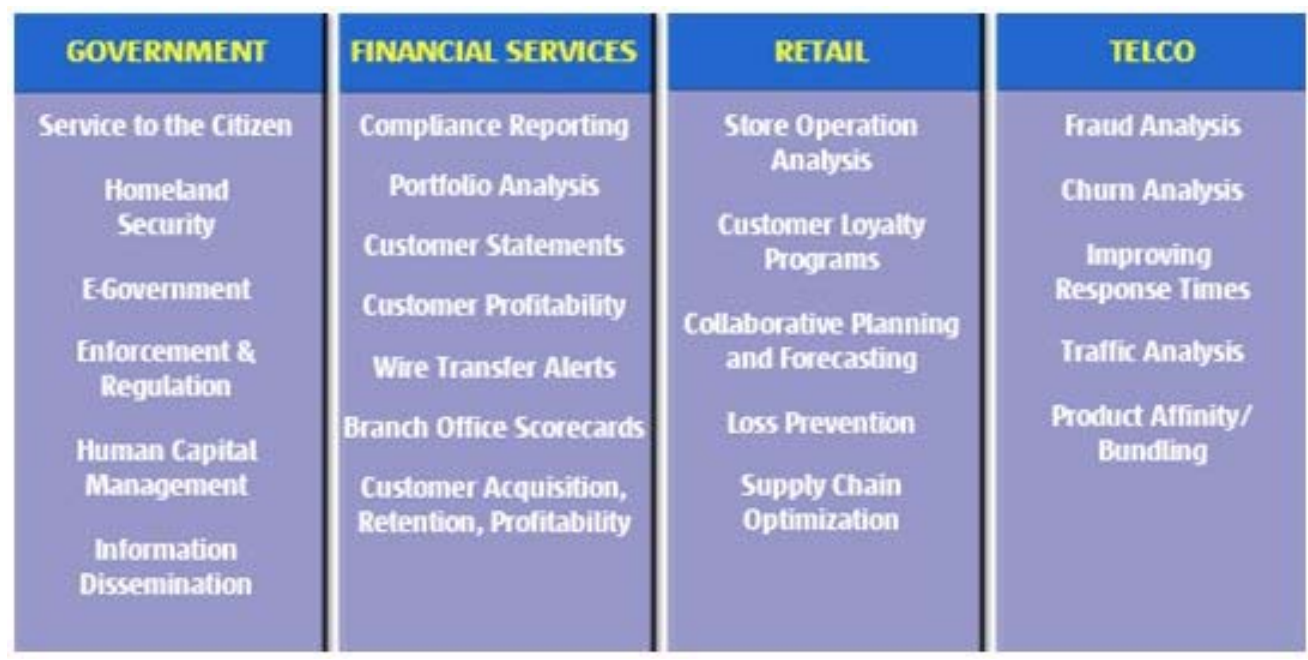

\section{How can the utilization of BI improve profitability in the telecommunication industry?}

One of the sub-problems of the hypothesis is to determine how BI can be utilized to improve the profitability of the organization. The research sought to address this sub-problem in terms of pure profit that can be earned by using BI and also in terms of what competitive advantage can be achieved.

\subsection{Improving profitability in terms of pure profit and return on investment (ROI)}

Business Objects, the leading vendor of BI software, believes that its solutions enable companies and organizations to:

- improve revenue and profits by acquiring and retaining high-value customers;

- reduce costs through more effective and responsive management;

- automate compliance with regulatory reporting requirements; and

- improve customer loyalty through improved quality and superior service delivery (Business Objects 2005).

BI can increase cost savings. ROI calculations for a BI project can be approached in two ways: a) by measuring efficiencies in information distribution; or b) by measuring business execution improvements that result from better, faster decision-making. The first approach is easy to measure and easy to execute, but it holds relatively small returns. The second approach is the opposite: hard to measure and hard to execute, but it offers huge returns. One can save little streamlining older reporting processes, but much greater opportunities are available when decision-making processes are significantly improved and key business processes are redefined. For example, an organization within the telecommunication industry has 15 people working full time preparing and distributing reports to users. Of those 15 people, ten focus exclusively on difficult ad hoc reports and queries that require pulling data together from multiple sources. If a BI initiative can cut in half the time to create and distribute these reports, the cost savings would be a reduction of five personnel. These personnel could add value by being productive in other key areas (Sun Microsystems 2006).

BI enables knowledge workers to work smarter, not harder. The fiscal impact of adding BI to the corporate decision support arsenal varies within different companies and industries. Three examples of ways in which effective BI has helped enterprises include the following:

- By analysing the root causes of product failure, a major manufacturing company was able to work with its suppliers to reduce the rate of product defects by one-quarter of $1 \%$ per day, generating savings of more than R14 million annually, not to mention having an impact on customer satisfaction.

- A large international portfolio management firm conservatively projected that by identifying and focusing on the top $20 \%$ of its clientele, transactions would increase by one-half of $1 \%$ per day, creating a daily revenue increase of R35 million. 
- By analysing customer behaviour and developing attrition, acquisition, retention and growth models, a major international technology supplier determined that it could increase annual revenues by more than R700 million and profits by almost R70 million (Lorenzo, Peters and Robskovsky 2002:91-93).

These anecdotes provide a few examples of the impact BI can have on top and bottom line revenues as well as on cost reductions. ROI analyses by BI adopters in various industries suggest that it is not unreasonable to expect a $500 \%$ or greater ROI with BI. It is indisputable that a company can gain significant business benefits through BI adoption. Outsourcing ones BI infrastructure to an experienced partner not only helps maximize ROI, but also helps one realize these returns more quickly than an in-house environment might (Lorenzo et al. 2002:91-93).

In addition to the obvious financial benefits, there are many other tangible and intangible benefits of BI. Placing intelligence about the company in the hands of executives enables senior management to run the company better, while intelligence available at the fingertips of mid-level management and frontline knowledge workers enables far more accurate decision making and supports a more productive and effective workplace. These benefits, of course, are not without substantial cost of ownership for an in-house BI environment. BI outsourcing offers the added advantage of reducing capital investment by shifting the costs of maintaining a state-of-the-art BI environment to the outsourcing provider.

Hinshaw (2004), the Chief Technical Officer and co-founder of Netezza Corporation, argues that ROI can be measured in two ways. There is the quantitative measurement of increased performance and decreased costs. If companies can make better, faster and more informed decisions, due to the comprehensive analyses of all their available data, they are able to take advantage of opportunities more effectively or head off problems before they happen. If organizations can accomplish this with a lower upfront and ongoing maintenance systems approach, one can measure ROI by their bottom line. The second view is more qualitative. If a company's BI infrastructure allows it to begin to question everything - not just run scheduled reports, but begin to delve into the information as never before that company can unearth new trends and new information that it can use to a strategic advantage, making BI a very compelling tool. Another way in which BI can attribute to higher profits is in the ability to commit fewer resources to specific project initiatives.

\subsection{Improving profitability in terms of achieving a competitive advantage}

Organizations are required to make more decisions, more frequently and more accurately in shorter time periods, especially in the telecommunication industry due to rapid technological changes.

The amount of time between when a decision is made and when feedback is received (requiring a new decision) is becoming shorter and shorter. The ability to make intelligent business decisions quickly is imperative to remain competitive. Over the past few years, BI systems have been used to understand and address back office needs such as efficiency and productivity. Now organizations are increasingly using BI to analyse customer behaviour, understand market trends and search for new opportunities. The ability to make sense of oceans of data quickly can be a competitive advantage, making BI software essential for many companies.

Gilad and Gilad (1988) agree, stating that with structured BI programs, organizations are better able to:

- track current and potential competitors;

- analyse markets;

- develop profitable new products;

- determine likely candidates for acquisition or merger; and

- monitor technological developments and keep abreast of a broad range of political, economic, social and legislative trends with significant impact on a company's future.

BI can only become a strategic weapon when business users are able to obtain answers (the information) to questions and make decisions in a time frame consistent with the requirements of a dynamic and agile organization. Factors driving the organization to consider BI include the need to service customers in a more personal and individual way, the pace of technological development and 
achieving a sustainable competitive advantage (Erasmus 2002).

\section{What contribution can management make when utilizing BI in the telecommunications industry?}

Management has a key role to play in terms of implementing BI in the telecommunications industry. It is management's role to ensure that not only is the necessary BI software purchased and implemented, but also that the necessary data are efficiently analysed and disseminated to ensure the survival of the organization.

The responsibility for deploying a BI initiative lies with the chief information officer (CIO), the IT general manager or the chief technical officer (CTO). There is a general trend towards CIOs becoming more business orientated rather than merely technically competent. This change is taking place since the CIO now manages both business analysts and the technical staff.

Implementing BI will be one of the most difficult tasks a CIO has to endeavour as he or she must ensure that the core organizational information systems are standardized so that it can be easily integrated with this architecture. He or she generates business requirements and participates in coordination of overall data architecture, develops and maintains BI plans and interprets business needs into functional requirements and manages the entire lifecycle for IT deliverables.

Furthermore, it can be argued that change must be addressed in a competent and professional manner when implementing a BI infrastructure. Fear of change is a normal human reaction as people become anxious that technology will replace their jobs, and they also become concerned that they may be forced to learn new technological skills. This is particularly daunting for older staff.

Another viable option that managers are beginning to consider is the outsourcing of their entire organization's BI. BI can be outsourced to an application service provider (ASP). An ASP manages an organization's operated software at its data centre allowing customers access online under a service contract. The first wave of ASPs was application outsourcers, who hosted software packages from established enterprise software vendors such as SAP, Peoplesoft and Oracle (Loosely Coupled 2004). BI outsourcing is a newly emerging option for companies seeking to launch or expand their BI capabilities. It offers significant benefits for organizations that do not yet have mature BI practices, especially smaller enterprises that may be strapped for resources. However, the decision to outsource one's BI is not simple. It requires relinquishing control of core business data to an outsider. These data contain an organization's competitive secrets and business wisdom, which is why BI is so crucial in the first place. In addition to analytical expertise, effective BI requires general industry knowledge and specific company knowledge. Analysis must be driven by business needs and goals and must result in beneficial and actionable outcomes. It also can be argued that outsourcing BI is costlier than the alternative - a debatable but important consideration.

A BI architecture comprises both hardware and software solutions as they are necessary for successful BI. An in-house BI environment must minimally include one or more dedicated database servers that are separate from the company's transactional systems. These servers must have the capacity to house large volumes of current and historical data and to process that data efficiently. There is ongoing debate about which is the best architecture for data warehousing environments, but traditional architectures consist of an ODS, a central data warehouse and multiple subject data marts.

Required software for a comprehensive BI environment includes the following:

- ETL software: For sourcing data from transactional and legacy systems and for transferring data from a data warehouse to data marts

- Data hygiene software: Software to enable data cleansing and quality improvement activities such as merging data from multiple sources, purging invalid or corrupt data, and eliminating duplicate records

- RDBMS: Relational database software required for ODSs, data warehouses, and relational OLAP data marts 
- Multidimensional database management software (MDDBMS): Software necessary to implement OLAP data marts

- Reporting software: Software such as Crystal Reports required for enterprise reporting against the relational data marts

- OLAP reporting tools: Tools from vendors such as Cognos, Business Objects and MicroStrategy required for generating meaningful multidimensional reports and querying against multidimensional data marts

- Data visualization software: Tools for plotting data onto 2-D and 3-D charts, graphs and other visualization techniques

- Statistical analysis software: Software that facilitates descriptive and predictive analysis or modelling using complex statistical methods such as logistic and linear regression

- Data mining software: Descriptive and predictive analysis or modelling using machine-learning methods, such as neural networks, decision trees and clustering, is provided by powerful data mining applications such as SAS Enterprise Miner, IBM Intelligent Miner, SPSS Clementine and others

- Development and support tools: A suite of database design and programming productivity software needed by database administrators (DBAs), data modellers, data architects, developers and other BI specialists.

It is clear that the cost to implement a full BI infrastructure can be an expensive exercise.

\section{Empirical survey}

The telecommunication industry comprises two segments namely service providers and global subsidiaries. The service providers in South Africa are composed of four major players namely Vodacom, MTN, Cell-C and Telkom. The global subsidiaries are composed of Nokia, Motorola, Sony Eriksson, Siemens, Alcatel, Samsung and others such as Transtel.

The study carried out was inductive in nature because it was prompted by a specific empirical question which was further investigated to determine whether utilization of BI will contribute towards increased profits in the telecommunication industry.

Triangulate research methodology was used which makes use of quantitative research, qualitative research as well as the personal experience of the researcher. The findings will be tested against further data collected with a view to testing the plausibility of the hypothesis and to facilitate the posit variables and relationships between the categories.

The qualitative research required that the author make various decisions during the studies. These decisions are shared with the reader so that a spirit of openness can be built between the reader and the researcher. The data features as the heart of the research study and a sense of place for the data is retained. The method of data collection was kept as simple as possible because in qualitative research the complexity is in the data.

A degree of reduction in the data is always present, and because it was deemed to be important, the reader is given a sense of where and how the data was obtained, how it was generated and collected and what its context was prior to being separated in analysis.

\subsection{Survey sample}

The population was the collective of the telecommunication industry in South Africa. The sample was the major telecommunication service providers in South Africa. Each service provider is referred to as a sampling unit.

The quantitative survey was a structured and anonymous survey that was e-mailed to direct respondents in the sample after initiating a discussion with the respondent. The author undertook not to disclose the names of the service providers and further not to link any analyses with the respective service providers. 
A total of 24 surveys were e-mailed and the respondents were given a period of two weeks in which to respond. A response of $25 \%$ was returned which is deemed to be able to portray a reasonable reflection for the research undertaken.

\subsection{Questionnaire}

The questionnaire was aimed at establishing the basic details of whether the targeted organization understood the concept of BI, whether the specific organization implemented BI practices, and finally of determining whether BI could provide profit maximization if implemented effectively.

The questionnaire is a mixture of both a factual and subjective nature and special attention was paid to the construction of the subjective sentences because answers are sensitive to changes in wording, emphasis and sequence.

A group of three independent respondents who were not involved in the telecommunication industry were tested to determine whether the questions are easy to understand. As a result of their inputs, the phraseology of four questions was amended and an additional question was inserted.

The questionnaires were distributed by way of e-mail and the respondents were given a two-week period to respond. This lack of control could reduce reliability (Chenail 1995). However, this threat is limited since the questions were objectively posed and the exact time of measurement is unlikely to influence the responses made.

Additional primary data were obtained through six structured interviews with senior telecommunication staff. The main advantage of using interviews is that these increased the sample size and also contributed towards creating a benchmark for accuracy of the data received.

\subsection{Data analysis}

\subsubsection{Quantitative analysis}

The questionnaire was based on Likert scaling, which allowed for respondents to choose an option from the scale as follows:

1 = not interested; 2 = no; 3 = maybe; 4 = somewhat; 5 = yes.

A total of $67 \%$ of the organizations indicated that they understand what BI is (Table 2). It is notable that none of the respondents indicated that they did not have an understanding of the concept although $33 \%$ had a vague understanding of what the concept entails. This is of concern since BI is not a new concept and senior staff in the telecommunications industry should have a firm grasp of it.

Table 2 Understanding of the concept of business intelligence

\begin{tabular}{|c|c|c|c|c|c|c|c|c|c|c|}
\hline \multicolumn{11}{|c|}{ RESPONSE } \\
\hline \multicolumn{2}{|c|}{1} & \multicolumn{2}{|c|}{2} & \multicolumn{2}{|c|}{3} & \multicolumn{2}{|c|}{4} & \multicolumn{2}{|c|}{5} & \\
\hline $\mathrm{N}$ & $\%$ & $\mathrm{~N}$ & $\%$ & $\mathrm{~N}$ & $\%$ & $\mathrm{~N}$ & $\%$ & $\mathrm{~N}$ & $\%$ & TOTAL \\
\hline 0 & 0 & 0 & 0 & 0 & 0 & 2 & 33 & 4 & 67 & 100 \\
\hline
\end{tabular}

Half of the respondents indicated that they currently implement BI practices and techniques (Table 3). Of the respondents $33 \%$ indicated that BI practices could currently be in the process of being implemented. This could be ascribed to the fact that the respondents were in the technical field and had no knowledge of BI processes.

Table 3 Organizations currently implementing BI practices and techniques

\begin{tabular}{|c|c|c|c|c|c|c|c|c|c|c|}
\hline \multicolumn{10}{|c|}{ RESPONSE } \\
\hline \multicolumn{2}{|c|}{1} & \multicolumn{2}{|c|}{2} & \multicolumn{2}{|c|}{3} & \multicolumn{2}{|c|}{4} & \multicolumn{2}{|c|}{5} & \\
\hline $\mathrm{N}$ & $\%$ & $\mathrm{~N}$ & $\%$ & $\mathrm{~N}$ & $\%$ & $\mathrm{~N}$ & $\%$ & $\mathrm{~N}$ & $\%$ & TOTAL \\
\hline 1 & 17 & 0 & 0 & 2 & 33 & 0 & 0 & 3 & 50 & 100 \\
\hline
\end{tabular}


The questions are aimed at the perceptions of the respondents. Clearly, there was a perception that BI practices alone did not yield tangible benefits (Table 4). It is disappointing that only $40 \%$ of the respondents believed that BI practices provide a possible benefit. Implementation is always the most difficult part of any process and this is illustrated by the perceptions of the respondents.

Table 4 Perceived effectiveness rating of the BI practices

\begin{tabular}{|c|c|c|c|c|c|c|c|c|c|c|}
\hline \multicolumn{10}{|c|}{ RESPONSE } \\
\hline \multicolumn{2}{|c|}{1} & \multicolumn{2}{|c|}{2} & \multicolumn{2}{|c|}{3} & \multicolumn{2}{|c|}{4} & \multicolumn{2}{|c|}{5} & \\
\hline $\mathrm{N}$ & $\%$ & $\mathrm{~N}$ & $\%$ & $\mathrm{~N}$ & $\%$ & $\mathrm{~N}$ & $\%$ & $\mathrm{~N}$ & $\%$ & TOTAL \\
\hline 0 & 0 & 1 & 20 & 2 & 40 & 2 & 40 & 0 & 0 & 100 \\
\hline
\end{tabular}

Of the respondents, 33\% indicated that they were currently implementing BI technologies (Table 5). This is $17 \%$ less than those who indicated that their organizations were implementing BI processes. The question arises whether it is possible to implement practices without also implementing BI technologies to support the processes. The $17 \%$ difference can possibly be ascribed to a disconnection between awareness of processes that are implemented and technologies that are implemented in support thereof.

Table 5 Organizations currently implementing BI technologies

\begin{tabular}{|c|c|c|c|c|c|c|c|c|c|c|}
\hline \multicolumn{10}{|c|}{ RESPONSE } \\
\hline \multicolumn{2}{|c|}{1} & \multicolumn{2}{|c|}{2} & \multicolumn{2}{|c|}{3} & \multicolumn{2}{|c|}{4} & \multicolumn{2}{|c|}{5} & \\
\hline $\mathrm{N}$ & $\%$ & $\mathrm{~N}$ & $\%$ & $\mathrm{~N}$ & $\%$ & $\mathrm{~N}$ & $\%$ & $\mathrm{~N}$ & $\%$ & TOTAL \\
\hline 0 & 0 & 1 & 17 & 0 & 0 & 3 & 50 & 2 & 33 & 100 \\
\hline
\end{tabular}

None of the respondents indicated that they perceived BI technologies to be ineffective (Table 6). Of the respondents $40 \%$ indicated that they believed the implementation of BI technologies provided a benefit. This contradicts the response of the effectiveness rating of the BI processes where $0 \%$ indicated that implementation was clearly perceived to be effective.

Table 6 Perceived effectiveness rating of the BI technologies

\begin{tabular}{|c|c|c|c|c|c|c|c|c|c|c|}
\hline \multicolumn{11}{|c|}{ RESPONSE } \\
\hline \multicolumn{2}{|c|}{1} & \multicolumn{2}{|c|}{2} & \multicolumn{2}{|c|}{3} & \multicolumn{2}{|c|}{4} & \multicolumn{2}{|c|}{5} & \\
\hline $\mathrm{N}$ & $\%$ & $\mathrm{~N}$ & $\%$ & $\mathrm{~N}$ & $\%$ & $\mathrm{~N}$ & $\%$ & $\mathrm{~N}$ & $\%$ & TOTAL \\
\hline 0 & 0 & 0 & 0 & 1 & 20 & 2 & 40 & 2 & 40 & 100 \\
\hline
\end{tabular}

The response of $66 \%$ of the respondents who indicated that their budgetary spend is confidential can be interpreted to mean that spending on BI applications could be deemed to provide a competitive advantage (Table 7). This is the reason why the respondents chose not to respond to the question. It is notable that $34 \%$ indicated that they do indeed budget for BI applications.

Table 7 Estimated budgetary spend per organization on BI applications (data warehouse and middleware excluded)

\begin{tabular}{|c|c|c|c|c|c|c|c|c|c|c|}
\hline \multicolumn{11}{|c|}{ RESPONSE } \\
\hline \multicolumn{2}{|c|}{1} & \multicolumn{2}{|c|}{2} & \multicolumn{2}{|c|}{3} & \multicolumn{2}{|c|}{4} & \multicolumn{2}{|c|}{5} & \\
\hline $\mathrm{N}$ & $\%$ & $\mathrm{~N}$ & $\%$ & $\mathrm{~N}$ & $\%$ & $\mathrm{~N}$ & $\%$ & $\mathrm{~N}$ & $\%$ & TOTAL \\
\hline 0 & 0 & 1 & 17 & 1 & 17 & 0 & 0 & 4 & 66 & 100 \\
\hline
\end{tabular}

$1=\mathrm{R} 0-\mathrm{R} 10000 ; 2=\mathrm{R} 100001-\mathrm{R} 500000 ; 3=\mathrm{R} 500001-\mathrm{R} 2000000 ; 4=\mathrm{R} 2000000>$; 5 = Confidential 
A total of $66 \%$ noted that effectively implementing BI would increase profits (Table 8). No negative responses were received in answer to this question. This response affirms the hypothesis of this research.

Table 8 Effective implementation of BI will provide profit maximization

\begin{tabular}{|c|c|c|c|c|c|c|c|c|c|c|}
\hline \multicolumn{11}{|c|}{ RESPONSE } \\
\hline \multicolumn{2}{|c|}{1} & \multicolumn{2}{|c|}{2} & \multicolumn{2}{|c|}{3} & \multicolumn{2}{|c|}{4} & \multicolumn{2}{|c|}{5} & \\
\hline $\mathrm{N}$ & $\%$ & $\mathrm{~N}$ & $\%$ & $\mathrm{~N}$ & $\%$ & $\mathrm{~N}$ & $\%$ & $\mathrm{~N}$ & $\%$ & TOTAL \\
\hline 0 & 0 & 0 & 0 & 0 & 0 & 2 & 34 & 4 & 66 & 100 \\
\hline
\end{tabular}

Although there was agreement that the effective implementation of $\mathrm{Bi}$ would increase profits, there was clearly doubt as to the utilization of the BI applications (Table 9). This could be ascribed to a lack of training, a lack of knowledge about the subject and even to discrepancies between planning and implementation.

Table 9 Telecommunication industry is utilizing BI applications optimally

\begin{tabular}{|c|c|c|c|c|c|c|c|c|c|c|}
\hline \multicolumn{10}{|c|}{ RESPONSE } \\
\hline \multicolumn{2}{|c|}{1} & \multicolumn{2}{|c|}{2} & \multicolumn{2}{|c|}{3} & \multicolumn{2}{|c|}{4} & \multicolumn{2}{|c|}{5} & \\
\hline $\mathrm{N}$ & $\%$ & $\mathrm{~N}$ & $\%$ & $\mathrm{~N}$ & $\%$ & $\mathrm{~N}$ & $\%$ & $\mathrm{~N}$ & $\%$ & TOTAL \\
\hline 0 & 0 & 1 & 17 & 4 & 66 & 1 & 17 & 0 & 0 & 100 \\
\hline
\end{tabular}

\subsubsection{Qualitative research}

An additional six short-structured interviews were carried out with random respondents in the telecommunications industry. Great care was undertaken to ensure that the respondents understood the questions and that the responses were accurately recorded (Table 10).

Table 10 Use of BI in the telecommunications industry

\begin{tabular}{|l|c|c|}
\hline \multicolumn{1}{|c|}{ Themes } & Responses \\
\hline & N & \% \\
\hline Not aware of what competitors are doing & 5 & 85 \\
\hline Profits remain steady & 2 & 34 \\
\hline Competition increasing - BI will have to be implemented to gain competitive advantage & 4 & 68 \\
\hline Implementation is problematical & 6 & 100 \\
\hline Improved decision making will result in higher profits & 4 & 68 \\
\hline Future and 'what if' scenarios will lead to higher profits & 3 & 51 \\
\hline Identifying key and potential customers will lead to higher revenue & 5 & 85 \\
\hline
\end{tabular}

Implementation of BI process and technology was clearly a problem as $100 \%$ of the respondents indicated this weakness restricts their organization from profit maximization.

When asked whether the telecommunication is optimally utilizing BI, $68 \%$ of the respondents indicated that this could become a key strategy to merely survive in the sector since new competitors were continually entering into the telecommunications sector.

The respondents replied that if BI is effectively implemented, it could lead to addressing the two key areas of strategic decision making which are clearly identifying future scenarios (51\%) and identifying key and potential customers (85\%).

It is notable that $85 \%$ of the respondents stated that they were not aware of what their competitors were doing in terms of BI processes. The respondent who was aware of what his or her competitors 
were doing had an advantage.

\subsection{Findings}

The findings revealed that $\mathrm{BI}$ is paramount for the telecommunications industry to remain competitive. This intelligence can improve the decision making process which will lead to the organization increasing its profits.

The following findings were gleaned from the research undertaken:

- The full benefits of BI are not wholly understood by organizations.

- An effective managed BI infrastructure gives an organization a sustainable competitive advantage since it can assist an organization to retain high-value customers through improved quality and superior service delivery, and reduce costs through more effective and responsive management.

- There is no benefit to be gleaned from implementing stand-alone BI processes. BI processes must be supported by BI technologies in order to reap the full benefit.

- BI applications are being utilized but not to the full potential in the telecommunication industry. This can be ascribed to a lack of knowledge, a shortage of technical skills in South Africa and a lack of training.

- Weak implementation of both BI processes and BI technologies is a drawback; one cannot survive without the other; and

- Effective implementation of BI does lead to increased profits as improved decision making will result in higher profits, future 'what if' scenarios will lead to higher profit, and identifying key and potential customers will generate higher revenue.

\section{Recommendations}

Owing to the high cost and the complex nature of $\mathrm{BI}$ architecture, it is recommended that only companies with 100 or more employees should consider implementing BI. Although the telecommunication market is stagnant at present, the big four service providers must prepare themselves for more competition as a second national operator (SNO) is currently underway and rumours of Virgin entering the cellular industry abound.

The entrance of a SNO will present companies with a challenge to be more innovative in order to remain competitive and not lose market share. BI can help to address these challenges.

It is recommended that organizations in the telecommunication industry should implement a BI infrastructure. A BI application should be implemented once the stakeholders in the organization are equipped and trained to garner maximum benefit from the application.

When considering BI implementation, an organization should automate its key processes with modern technology. This means that key processes should be in place before the technologies are implemented because these processes serve as the basis of the organizations' business model. The technological aspect of the BI infrastructure can be implemented in two formats, namely in a bundled version and an unbundled version. A bundled BI architecture is where the data warehouse, data marts, middleware and BI applications are produced and maintained by the same IT vendor (Oracle $10 \mathrm{~g}$ provides such a solution). This route is recommended since it is easier to implement and maintain as the components are easy to integrate with each other, and particularly where a large budget is available. Unbundled BI architecture comprises a data warehouse, data marts, middleware and BI applications that are produced and maintained by different IT vendors (data warehouse could be Microsoft SQL Server while the BI application could be developed by Business Objects - Business Objects is the leading vendor of BI technologies and has a valuable reputation in the BI industry). This serves as a great advantage as the corporations can decide what functionality to include and what combination of different vendors will provide the BI. However, these solutions tend to be more expensive than the former. 
an application service provider (ASP). In this way, a CIO can concentrate on other business issues while knowing that the organization's BI is in the hands of professionals. BI outsourcing is one of the newest offerings in the IT services industry. If it is successfully executed, the benefits substantially outweigh the drawbacks.

Successful execution, however, requires the active and interactive involvement of both the BI service provider and the client company. Furthermore, effective BI outsourcing requires a high degree of trust in the service provider, along with ironclad data security mechanisms. However, if all runs smoothly, outsourcing is a definite option that organizations should consider. A drawback with this approach is that companies are reluctant to hand over important and sensitive information to an outsider.

The weakness in implementation should be addressed as a matter of urgency. Senior management should focus on the results of the implementation process by receiving regular report-backs from the responsible persons and sanctions should be imposed if targets are not met. This could be supplemented with frequent training sessions to ensure that all employees are up to date with current trends.

\section{Linking general theory and concepts to practice}

Comparisons can be drawn between theories based on the literature research and the findings as recorded above. The literature review opens with the statement that organizations are finding it increasingly difficult to increase profits as competition in the marketplace continually pressurizes margins. McLeod and Schell (2001) argue that BI is an addition of competitive intelligence and state that fierce global competition has forced companies to rethink the way in which they gather information.

The telecommunications industry is heading towards a fiercely competitive environment and it is clear that some of the organizations are pro-actively finding innovative methods to gather intelligence and utilizing this intelligence to achieve a competitive advantage and higher profits.

Hinshaw's (2004) contention that organizations should place themselves in a position to make better, faster and more informed decisions in order to head off problems before they happen is a fundamental argument supporting effective utilization of BI applications and processes. He goes further to state that if an organization effectively manages the information then it will enter the innovation arena that will attract opportunities and avoid problems. The research proved that an effectively managed BI infrastructure gives an organization a sustainable competitive advantage.

BI can, however, only become a strategic tool when business users are able to obtain information that is applicable to the decisions that must be made as stated by Erasmus (2002). The findings confirm that BI applications are being utilized but not to the fullest potential. It is vital that an organization can access the information it needs, at the moment that this information is required. Analysis must be driven by the organization's needs and goals and must result in beneficial outcomes.

Gilad and Gilad's (1988) assertion that was made more than 15 years ago still holds true today. They stated that the utilization of structured BI programmes will result, inter alia, in the ability to develop profitable new products, invest heavily in research and development, analyse markets and keep abreast of a broad range of socio-economic, legislative and political trends. Business Objects (2005) goes further by stating effective and responsive management could reduce costs and thus improve the bottom line.

All of these predictions are relevant to the telecommunications industry since competition is the order of the day and cost cutting and price skimming are no longer effective ways of producing a competitive advantage. Effective implementation of BI will therefore lead to improved profits.

\section{Conclusion}


BI therefore does improve profitability in the telecommunication industry and can help management to define strategies, support decision making, search for opportunities, identify problems and substantiate actions. However, this is dependent on the effective implementation of both BI process and BI technologies. Owing to the minimal understanding of BI by employees, employees must be trained not only to operate the BI tools and techniques, but they should also be trained to accept the necessary change that is required as technological advances are continually made.

\section{References}

Business Objects. 2005. Business intelligent solutions. [Online]. Available WWW: http://www.businessobjects.com/solutions/default.asp (Accessed 28 October 2005).

Chenail, R.J. 1995. The qualitative report. [Online]. Available WWW:

http://www.nova.edu/sss.qr/qr2-3/presenting.html (Accessed 28 October 2005).

Dutta, S., Berend, W. and Dalebout, A. 1997. Designing management support systems: using an integrative perspective. Communications of the ACM 40(6).

Erasmus, M. 2002. Business intelligence: issues for management. [Online]. Available WWW: http://general.rau.ac.za/infosci/raujournal/default.asp?to=editvol4nr4 (Accessed 29 October 2005).

Feng, C. 2002. Multidimensional databases. Hong Kong: Perspective Hall.

Forgionne, G.A. and Kohli, R. 2000. Management support system effectiveness: further empirical evidence. Journal of the Association for Information Systems 1(3).

Gartner Group. 2001. Business intelligence. [Online]. Available WWW:

http://www.gartner.com/it/products/research/asset_129487_2395.jsp (Accessed 22 August 2005).

Gilad, B. and Gilad, T. 1988. The business intelligence system: a new tool for competitive advantage. New York: Amacom.

Hasheem, N. 2001. SAP business intelligence: what is it? [Online]. Available WWW:

http://searchsap.techtarget.com/onlineEventsTranscript/0,289691,sid21_gci535218,00.html (Accessed 3 October 2005).

Hinshaw, F. 2004. Ask the expert. [Online]. Available WWW:

http://www2.cio.com/ask/expert/2004/questions/question1955.html (Accessed 10 October 2005).

Laudon, K.C. and Laudon, J.P. 2004. Management information systems: managing the digital firm. New Jersey: Prentice Hall.

Lorenzo, J., Peters, A. and Robskovsky, D. 2002. Information systems: show me the money. London: Kurt Emblem Publishers.

Loosely Coupled. 2004. Application service provider. [Online]. Available WWW:http://looselycoupled.com/glossary/ASP (Accessed 28 October 2005).

McLeod, R. and Schell, G. 2001. Management information systems. New Jersey: Prentice Hall.

Rob, P. and Coronel, C. 2002. Database systems: design, implementation and management. USA: Course Technology.

Sun Microsystems. 2006. Business intelligence and data warehousing Sun Microsystems. [Online]. Available WWW: http://businessintelligence.ittoolbox.com/browse.asp?c=BIWhite+Papers\&r= http\%3A\%2F\%2Fwww\%2Esun\%2Ecom\%2Fstorage\%2Fwhite\%2Dpapers\%2Fbidw\%2Epdf 
(Accessed 1 November 2005).

Turban, E., McLean, E., Wetherbe, J., Bolloju, N. and Davison, R. 2002. Management technology for management: transforming businesses in the digital economy. New York: John Wiley.

Wikipedia. 2005a. Business intelligence. [Online]. Available WWW:

http://en.wikipedia.org/wiki/Business_intelligence (Accessed 15 August 2005).

Wikipedia. 2005b. Competitive intelligence. [Online]. Available WWW:

http://en.wikipedia.org/wiki/Competitive_intelligence (Accessed 23 August 2005).

\section{Disclaimer}

Articles published in SAJIM are the opinions of the authors and do not necessarily reflect the opinion of the Editor, Board, Publisher, Webmaster or the Rand Afrikaans University. The user hereby waives any claim he/she/they may have or acquire against the publisher, its suppliers, licensees and sub licensees and indemnifies all said persons from any claims, lawsuits, proceedings, costs, special, incidental, consequential or indirect damages, including damages for loss of profits, loss of business or downtime arising out of or relating to the user's use of the Website. 